\title{
Crisis económica y profesionalización en el campo de la educación ambiental: comparativa 2007-2013 en Galicia
}

Pablo Ángel Meira Carteal

María Barba Núñez!

Juan José Lorenzo Castiñeiras'

\section{Resumen}

El objetivo del artículo es aportar evidencias que permitan valorar cómo está incidiendo en el campo de la educación ambiental (en adelante EA) la crisis social y económica que padece la sociedad española. Para ello se analiza, a través de una encuesta online, una muestra de profesionales que trabajan en este campo en Galicia, utilizando como principal perspectiva analítica la comparación de su situación socio-laboral en el albor de la crisis, año 2007, con la experimentada a principios de 2013. Pese a centrarse territorialmente en Galicia, el análisis apunta interpretaciones de la realidad social que pueden ser extrapolables a otros contextos, proponiendo una lectura compleja que inscribe el desmantelamiento del campo de la EA dentro de la degradación de un estado del bienestar que era incipiente, con el debilitamiento sistemático de los servicios y recursos públicos que trabajan por el bien común. Los datos evidencian este desmantelamiento, así como ciertas debilidades internas del campo de la EA que lo hacen especialmente vulnerable. Ante esta situación, se defiende la necesidad de una política pública de EA, que debe tener en la Administración Autonómica su principal actor responsable, que contribuya a consolidar y estabilizar el campo. El propio campo se enfrenta al reto de conquistar un papel protagonista en la construcción participada de dichas políticas.

\section{Palabras clave}

Educación ambiental - Ocupación profesional - Encuesta online. 


\title{
Economic crisis and professionalization in the field of environmental education: comparative 2007-2013 in Galicia
}

Pablo Ángel Meira Cartea'

María Barba Núñez'

Juan José Lorenzo Castiñeiras

\begin{abstract}
The aim of this article is to provide evidence for assessing how the social and economic crisis in Spanish society is influencing the area of environmental education (EE). Through an on-line survey, professionals working in this field in Galicia were asked to compare their occupational situation at the beginning of the crisis, in 2007, to what they were experiencing at the beginning of 2013. The analysis is based on data obtained from this survey. Though territorially focused on Galicia, the analysis offers interpretations of social reality that can be extrapolated to other contexts. This complex reading inscribes the dismantling of the environmental education field within the apparent deterioration of an emerging welfare state and the weakening of services that work for the common good. The data describe the dismantling of EE, along with certain internal weaknesses that make it particularly vulnerable to external threats. The article also defends the need for EE public policy, primarily as a competence of the Galician Autonomous Community. The regional Administration should play the key role in helping to consolidate and stabilize EE, granting it a leading role in the participatory construction of such policy.
\end{abstract}

\section{Keywords}

Environmental education - Professional occupations - Online surveys.

I- Universidad de Santiago de

Compostela, Galicia, España.

Contacts: pablo.meira@usc.es;

maria.barba@usc.es;

juanjo.Iorenzo@usc.es 


\section{Introducción}

La aproximación retrospectiva y longitudinal al campo de la educación ambiental (en adelante EA) en Galicia, a partir de la comparación entre las condiciones de trabajo en el año 2007 respecto a la que experimentada a principios de 2013, quiere testar dos hipótesis.

La primera se refiere a la intuición extendida entre los agentes que operan en el campo de la EA de que la crisis está sirviendo para desmontar lo laboriosamente construido en las cuatro décadas de trayectoria que este campo tiene en Galicia y en el conjunto del Estado español. El período más pujante de esta trayectoria coincidió, precisamente, con la década que precedió a la crisis, abarcando el último lustro del siglo XX y el primero del siglo XXI.

Entre los factores que pueden explicar la retracción que experimenta la EA destacan la disminución de los presupuestos públicos y el enfriamiento de la actividad económica general como consecuencias de la política de recortes aplicada en todos los niveles de la administración. En este sentido, es necesario destacar el peso que tiene en la EA la financiación y las actividades promovidas por las administraciones o la dependencia que reconocen los agentes privados, empresas o actores del sector, de los presupuestos públicos (SOTO; PARDELLAS, 2010).

La segunda hipótesis se refiere al impacto más agudo de la crisis sobre el campo de la EA en comparación con otros afines y con el impacto que está teniendo sobre la sociedad gallega y española en su conjunto. De ser así cabría esperar que la destrucción de empleo y la precarización laboral de los y las profesionales de la EA sean más intensas que en otros sectores. Existe la percepción de que la crisis está siendo instrumentalizada como coartada para legitimar la demolición de un ámbito incómodo para el sistema que, además, resulta prescindible sin asumir mayores costes políticos o sociales. Esta situación choca con las declaraciones nacionales e internacionales que identifican a la EA como una herramienta indispensable para construir sociedades que aspiren a ser ambiental, social y económicamente sostenibles.

Más allá de los intereses políticos, se dan una serie de factores, vinculados a su identidad y lógica de funcionamiento, que dotan de debilidad interna al campo y lo hacen dependiente de lógicas ajenas, situándolo en la actual posición de extrema vulnerabilidad.

Para analizar con cierta robustez metodológica el impacto de la crisis, el foco de esta investigación se centra en una dimensión estructural del campo, tanto por el peso que tiene en la caracterización de su identidad, como por las posibilidades que ofrece para conocer la lógica social de su funcionamiento. Esta dimensión es la situación profesional de las personas ligadas a la EA, en este caso en Galicia. El análisis de la situación profesional de un campo ofrece datos relevantes sobre su salud, sobre la importancia real que tiene para la sociedad y para sus instituciones, y también sobre los procesos que operan en la construcción de su identidad. Si el campo sometido a examen es la EA, la relevancia del análisis es, si cabe, mayor. Primero, por la carencia de estudios empíricos que exploren esta dimensión y, segundo, porque la retórica de las políticas educativas y ambientales atribuye a la EA un estatus de prioridad que, sospechamos, está lejos de cumplirse en la práctica.

\section{Tensiones e intereses en el desarrollo del campo de la educación ambiental}

Cuando se habla del campo de la EA y de los efectos de la crisis sobre él no se propone una simple analogía topológica. El uso de esta expresión parte de la comprensión de la EA como un campo en el sentido analítico que Pierre Bourdieu concedió a este concepto. Para Bourdieu (1997), un campo es un universo social intermedio, un espacio relativamente autónomo, dotado de sus propias leyes y reglas de funcionamiento, y que dispone, respeto al 
espacio social más amplio, de una autonomía más o menos acentuada. Según Brandão (2010), este pensamiento relacional aporta a quien investiga mayor rigor a la hora de percibir las características específicas de los objetos de estudio, que adquieren su sentido al definir la posición ocupada respecto a otros campos, así como su estructura interna.

Situar la atención sobre la situación profesional permite abordar el campo en su sentido identitario y socioeconómico, posición clave para desvelar la relación con otros campos de poder y para identificar las luchas internas entre los diferentes sectores que lo componen. Son varios los estudios que han examinado la situación socioprofesional de la EA en España (INEM, 2006; IMEDES, 2008; IRCUAL, 2009; SERANTES, 2013; OLIVER, 2013) y en Galicia (GUTIÉRREZ-ROGER, 2007; SOTO; PARDELLAS, 2010), o que han profundizado en la definición de un perfil profesional (SOTO, 2007; BAUTISTACERR0, 2009) para el caso español; estudios que permitieron avanzar sensiblemente en la consolidación, el reconocimiento social y la mejora de las condiciones laborales.

En su configuración interna, defendemos la opción de definir a la EA como un transcampo (MEIRA, 2009): un espacio social particular generado en la intersección de dos campos, el educativo y el ambiental, que aportan propiedades sociales diferentes y distintas lógicas de estructuración. Esta doble identidad opera como dilatador de la puerta de entrada al campo, dando cabida a personas con perfiles formativos y profesionales heterogéneos. La multidisciplinaridad puede ser un elemento positivo para su desarrollo, en la medida en que lo nutre de perspectivas de análisis e intervención diversas (GARCÍA, 2004). En esta línea, Caride defiende la necesidad de vincular la construcción de su identidad profesional $-\mathrm{y}$, por qué no, también académica- "a principios que reivindican la interdisciplinaridad $\mathrm{y}$ multiprofesionalidad, en coherencia con el carácter complejo, diferencial y plural de las tareas que debe desempeñar" (2002, p.33). Se presenta como un reto complejo ante el cual González Gaudiano (1998) aporta orientaciones para concretar una propuesta formativa que contribuya, desde el reconocimiento de su complejidad como campo de conocimiento, al proceso de profesionalización. La naturaleza híbrida es uno de los rasgos de la EA, un espacio multidisciplinar en el que conviven, no siempre harmónicamente, distintas culturas disciplinares, una diversidad enriquecedora pero que también dificulta su construcción identitaria.

La comprensión de la EA como campo implica un análisis de los conflictos que se producen en su interior en la pugna simbólica por definir su identidad. Uno de estos conflictos tiene que ver con la dualidad de los agentes: los que priman la dimensión ambiental frente a los que priman la educativa. La clasificación nacional de calificaciones profesionales (Ministerio de Educación, Cultura e Deporte) da cuenta de este conflicto, al inscribir el perfil formativo de Interpretación y Educación Ambiental (RD 814/2007'), así como el recién creado de Educación y Control Ambiental (RD 384/20112), en la familia profesional de Seguridad y Medio Ambiente, y no en la de Servicios Socioculturales y a la Comunidad. Decisión adoptada a pesar de que la EA en España tiene una trayectoria más vinculada a los estudios superiores de Ciencias de la Educación que a los de Ciencias Naturales, y de que su objeto sea, en rigor, esencialmente educativo.

Las clasificaciones profesionales asociadas al campo de la EA propuestas por diferentes organismos (INSTITUTO NACIONAL DE ESTADÍSTICA, 2012; JIMÉNEZ; LEIVA, 2010; IMEDES, 2008), también denotan la dificultad para establecer sus límites, lo que se traduce en taxonomías diversas en las que se habla de educador ambiental, técnico en información

1- Real Decreto 814/2007, de 22 de junio, por el que se complementa el Catálogo Nacional de Cualificaciones Profesionales, mediante el establecimiento de dos cualificaciones profesionales correspondientes a la Familia Profesional Seguridad y Medio Ambiente.

2 - Real Decreto 384/2011, de 18 de marzo, por el que se establece el título de Técnico Superior en Educación y Control Ambiental y se fijan sus enseñanzas mínimas. 
ambiental, coordinador de programas y centros de EA, comunicador ambiental, informador ambiental, técnico en EA, intérprete ambiental o monitor en la naturaleza. La lectura superficial de estas categorías permite visualizar la confusión con perfiles profesionales ajenos o tangenciales al campo, así como el predominio de la dimensión informativa y comunicadora, cuando la EA demanda la concreción de un perfil profesional nítido, orientado a la práctica y la transformación social frente a la simple transmisión de conocimientos (MUÑOZ-PEDREROS, 2014).

El artículo desarrolla el análisis del campo de la educación ambiental en dos partes. La primera busca la aproximación a su estructura socio-demográfica, atendiendo a las variables que definen el espacio social que constituyen y ocupan las educadoras y educadores ambientales. En la segunda parte se establece un análisis comparativo para valorar la evolución experimentada por el campo de la EA en Galicia, desvelando las relaciones de poder que llevan a su desmantelamiento.

\section{Diseño del estudio}

Para concretar este estudio se ha realizado una encuesta online a una muestra de personas que cumplen la condición de estar o haber estado vinculadas profesionalmente al campo de la EA en Galicia. El cuestionario se elaboró para captar sintéticamente la situación profesional, ocupacional y social de estas personas en el año 2007, justo antes de la fase más aguda de la crisis, y principios del año 2013, ya ejecutado el rescate bancario y con la sociedad española en estado de shock por la aplicación de las políticas de recortes. Esta técnica sustenta una de las líneas metodológicas del proyecto $L a$ educación ambiental en Galicia: análisis sociobiográfica de su construcción como campo, desarrollado por el Grupo de Investigación en Pedagoxía Social e Educación Ambiental (SEPA) de la Universidad de Santiago de Compostela (España), con cargo al Plan Galego 2011/2015 (Plan I2C) Convocatoria 2011.
Para acotar el universo de población del que extraer la muestra se adoptó como referencia el cálculo que recoge el Informe de empleo verde en una economía sostenible promovido por el Observatorio de la Sostenibilidad en España (JIMÉNEZ HERRERO; LEIVA, 2010) que cuantificó en 345 las personas ocupadas en Galicia en el ámbito de la educación y la información ambientales, tomando como referencia el año 2009. A pesar de la cuestionable precisión de esta cifra, no existe otra fuente primaria a la que recurrir ${ }^{3}$.

La dificultad para trazar con precisión los límites del campo de la EA e identificar quiénes están profesionalmente vinculadas a él, deriva en un obstáculo de orden metodológico. Esta cuestión se resolvió acudiendo al directorio de dos instituciones claves en la EA gallega: el Centro de Extensión Universitaria y Divulgación Ambiental de Galicia (CEIDA), re-fundado en el año 2001; y la Sociedade Galega de Educación Ambiental (SGEA), constituida en el año 2001. Estas instituciones generan relaciones con la práctica totalidad del universo potencial, constituyendo una opción metodológica aceptable para acceder a él y componer una muestra mínimamente representativa.

El CEIDA facilitó acceso a los correos electrónicos de quienes habían participado alguna vez en cursos de formación relacionados con la EA ofertados por este organismo, y la SGEA a los correos de las personas asociadas. Dada la especialización de ambas instituciones cabe esperar que la muestra refleje la heterogeneidad de perfiles y situaciones que caracterizan a las personas que se definen como profesionales en este campo. La muestra quedó establecida en 391 personas, a las que se les remitió el cuestionario elaborado.

Esta cifra resultó ser superior a la ofrecida por el informe del Observatorio para la Sostenibilidad en España (JIMÉNEZ HERRERO; LEIVA, 2010), pero la desviación no es grande

3- El informe del OSE - Observatorio para la Sostenibilidad en España destaca la dificultad para cuantificar los yacimientos de empleo ligados al ambiente "en la medida en que no existen datos oficiales ni encuestas que puedan cubrir el vacío de datos" (JIMÉNEZ HERRERO; LEIVA, 2010, p. 11). 
y permite fijar entre 350 y 400 el número de personas ocupadas en el sector en Galicia. El desajuste se explica por el carácter estimativo del estudio estatal y por la metodología utilizada para su cálculo, influyendo también la naturaleza difusa de las fronteras de la EA y la inestabilidad laboral del campo. Este factor no supuso un lastre metodológico importante ya que en el protocolo del cuestionario se solicitó a las personas pre-seleccionadas que, de no haber ejercido nunca como educadoras ambientales, no respondiesen.

La encuesta fue remitida por correo electrónico a 391 personas. Finalmente se obtuvieron 133 cuestionarios válidos, que quedaron reducidos a 101 tras un proceso de depuración. Si bien la mortalidad fue elevada en términos absolutos, la tasa de respuesta del $25,8 \%$ se considera satisfactoria y acorde con el procedimiento telemático empleado, alcanzando un nivel de representatividad suficiente. Toda vez que el universo de población inicial era de $\mathrm{N}=345$, y el nivel de repuesta ${ }^{4}$ fue del $n=101$, con un nivel de confianza de un 95\%, para $p=q=0,5$, el error absoluto muestral se fija en el $\pm 8,21 \%$.

Para cumplimentar el cuestionario se utilizó la aplicación web de realización de encuestas e-encuesta, que permaneció abierta desde el 27 de diciembre de 2012 al 28 de enero de 2013 . El e-encuestas es una aplicación web de Webtools S.L. que permite crear una encuesta personalizada y enviarla a un número ilimitado de personas, permitiendo un tratamiento anónimo de los resultados y control de duplicidades a través de la IP.

El cuestionario utilizado combina una extensión breve con la facilidad para ser contestado. Su estructura diferencia dos bloques: uno primero con nueve preguntas indaga en la información personal y está configurada con variables de segmentación; y un segundo bloque compuesto por doce preguntas con cuestiones centradas en la situación profesional

4 - Descartamos cuestionarios inválidos y de quienes ejercen como maestros o profesores dentro del sistema escolar (13 casos), por no resultar representativos de la coyuntura profesional del campo. y laboral de la persona, diseñado para explorar la evolución socio-profesional entre 2007 y el momento de realizar la encuesta. El cuestionario finaliza con dos escalas subjetivas en las que cada persona ha de valorar la correspondencia del trabajo que realiza con lo que piensa que debe ser la EA, la primera, y la satisfacción profesional, la segunda.

La información se trató con el programa de análisis estadístico SPSS. Se establecieron categorías para aglutinar las respuestas abiertas a partir de un primer análisis de las mismas y se agruparon aquellas preguntas cerradas que introducían varias opciones susceptibles de ser relacionadas entre sí. El SPSS facilitó la comparativa entre 2007 y 2013, así como el análisis de otras variables fundamentales para comprender la evolución de la situación sociolaboral de la EA en Galicia.

\section{El perfil socio-demográfico de los y las profesionales de la educación ambiental}

La aproximación a los y las profesionales de la EA en Galicia no puede hacerse desde su caracterización como un colectivo uniforme. Por el contrario, tal aproximación debe atender a las diferentes posiciones que definen el espacio social que constituyen y ocupan.

Lo primero que destaca es la marcada feminización del campo (figura 1), en el que las mujeres suponen el 68,3\% de la muestra. Los datos también expresan un potencial de renovación generacional limitado: la mayoría de los profesionales, el 62,4\%, se sitúa en el intervalo de edad entre los 30 y los 40 años, no contabilizándose casos en la categoría de menores de 25 años.

En la caracterización del núcleo familiar de las personas encuestadas, prácticamente tres de cada cuatro, el 71,3\%, declara no tener hijos ni otros familiares a su cargo. Esta es una cualidad muy relevante, máxime cuando el 87,1\% de las personas tiene más de 30 años de edad. Esta particularidad puede reflejar patrones 
Figura 1- Distribución en frecuencias según género y edad.

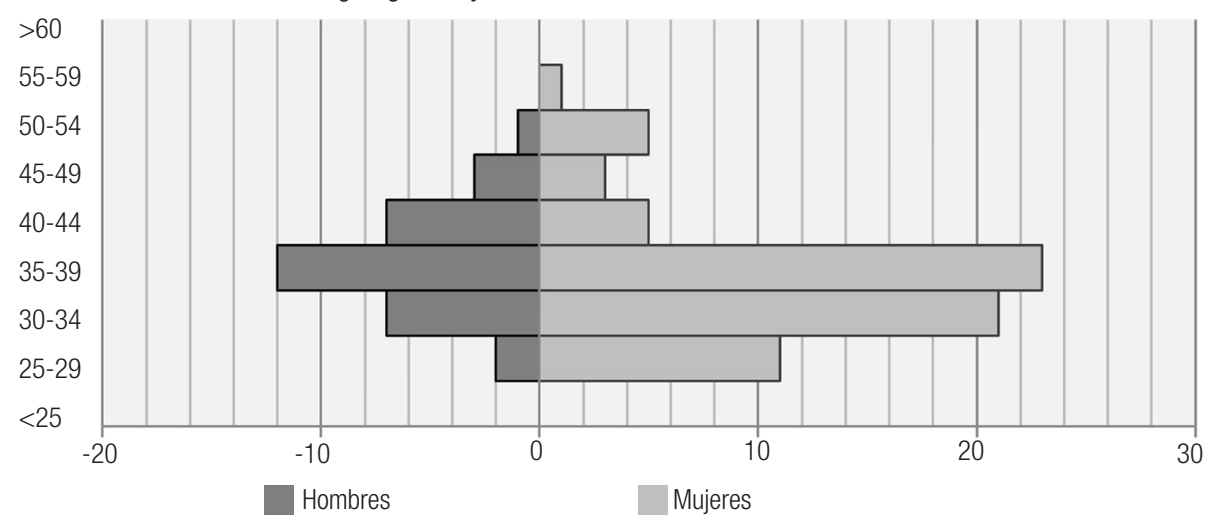

Fuente: Elaboración propia.

culturales asociados a proyectos vitales en los que la renuncia a tener descendencia es una elección consciente. Pero también puede obedecer a una trayectoria formativa larga, que inhibe y aplaza la decisión de tener descendencia, o a condicionamientos sociales y económicos vinculados a la precariedad del campo (salarios bajos, inestabilidad contractual, etc.). Esta parece una opción más probable atendiendo a los datos aportados por Gutiérrez Roger (2007), que interrogando en el 2005 a las educadoras y educadores ambientales de Galicia sobre esta cuestión apuntaba que, son madres y padres más del $85 \%$ de quien tiene condición de funcionariado, pero solo el 9,7\% de las personas asalariadas y desempleadas.

La situación familiar extrema es la que puede estar sufriendo el 5,9\% que declaran tener cargas familiares y no disponer de ninguna fuente de ingresos en su unidad de convivencia. A este porcentaje cabe agregar, dada la precariedad de los salarios que después se comentará, el 8,9\% que convive en un núcleo familiar con una única fuente de ingresos.

Con respecto al año de incorporación profesional al campo de la EA (figura 2), se aprecia una tendencia claramente expansiva entre 1996 y 2007, registrándose el mayor número de incorporaciones en el intervalo 2004-2007. En el último bienio considerado, 2012-2013, el ritmo de incorporaciones se sitúa por debajo del primer bienio de la serie. La inflexión que se constata a partir de 2007 visualiza el impacto de la crisis en el campo de la EA, haciéndolo cada vez menos atractivo como nicho profesional. El año de incorporación no presupone un ejercicio profesional continuado, pero permite visualizar los períodos expansivos del campo y, por lo tanto, su mayor capacidad para generar actividad y empleo.

Figura 2- Año de incorporación como profesional de la educación ambiental.

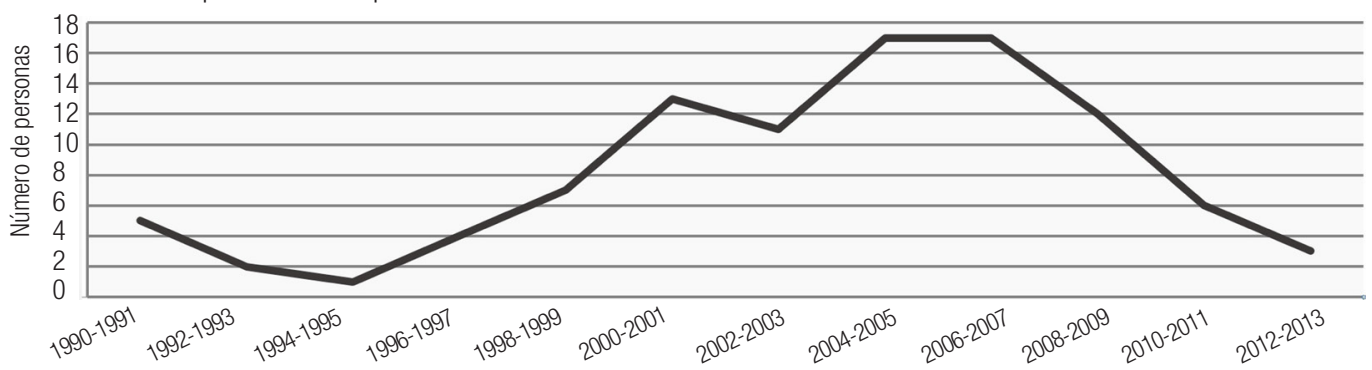

Nota: Distribución en frecuencias por bienios.

Año de inicio como profesional de la EA

Fuente: Elaboración propia. 
El incremento progresivo de incorporaciones que se inicia en el bienio 19961997 y alcanza su cénit en 2004-2005 puede estar asociado con la creación en 1997 de la Consejería de Medio Ambiente. Cabe destacar que dentro de su estructura funcionó el Centro de Información y Tecnología Ambiental (CITA), organismo que concentró las competencias autonómicas en materia de EA. En el proceso de institucionalización de la EA en Galicia, esta etapa supuso el impulso de líneas de trabajo específicas dentro de la administración autonómica con una intensidad sin precedentes. En esta coyuntura se incrementaron los apoyos destinados al tercer sector, a otras administraciones y a las empresas, para alimentar iniciativas de EA. Es la etapa en que se elaboró la Estratexia Galega de Educación Ambiental (1999), el primer intento de definir un marco explícito para orientar las políticas públicas de EA en Galicia.

Los datos que describen el perfil formativo de la muestra expresan el peso del capital académico entre los y las profesionales de la EA. El 94,0\% de la muestra declara poseer estudios de grado superior: el 88,1\% universitarios y el 5,9\% de ciclos superiores de formación profesional. Redundando más en este perfil, el 14,9\% afirma poseer más de una carrera universitaria o haber complementado su licenciatura o diplomatura con estudios de master, postgrado o doctorado. Estos datos permiten calificar a este colectivo profesional como hiper-formado. Esta visión contrasta con la imagen social de la EA como un campo débilmente cualificado que no requiere una formación muy especializada. Preferimos el concepto hiper-formación al de sobreformación, ya que este último transmite la idea negativa de un exceso de formación que superaría la cualificación necesaria para las tareas que requiere la EA, cuando entendemos que las funciones $\mathrm{y}$ responsabilidades que implica exigen un alto nivel de cualificación.

El informe del OSE ya destaca que "el nivel de formación en este sector es muy elevado en comparación con el promedio de la economía verde y de la economía española" (JIMÉNEZ HERRERO; LEIVA, 2010, p. 214). Los redactores del informe atribuyen esta característica a que la EA es una actividad intensiva en conocimiento que, en consecuencia, demanda a personas con titulación universitaria o formación profesional de nivel superior. Concordando con esta interpretación, este sesgo es más acusado en Galicia: en el sector de la EA, el OSE cifraba en el $66 \%$ las personas que poseían estudios universitarios a nivel estatal, porcentaje que alcanzaba el 88,1\% en Galicia.

Tabla 1- Distribución por frecuencias según titulación

\begin{tabular}{|c|c|c|c|c|c|}
\hline RAMA / TITULACIÓN & $n(\%)$ & RAMA / TITULACIÓN & $n(\%)$ & RAMA / TITULACIÓN & $n(\%)$ \\
\hline CIENCIAS EXPERIMENTALES & $73(45,1 \%)$ & CIENCIAS SOCIALES & $35(38,5 \%)$ & INGENIERÍAS & $13(14,3 \%)$ \\
\hline Biología & 32 & CIENCIAS DE LA EDUCACIÓN & $20(22 \%)$ & Ing. de Montes & 3 \\
\hline Cc. Ambientales & 5 & Pedagogía & 4 & Ing. Técnica & 5 \\
\hline Cc. del Mar & 3 & Cc. de la Educación & 3 & Forestal & 2 \\
\hline Química & 1 & Magisterio & 7 & Ing. Agrónoma & 2 \\
\hline & & Educación Social & 6 & Ing. Técnica & 1 \\
\hline & & Sociología & 2 & Agrícola & \\
\hline & & Trabajo Social & 2 & Ing. en & \\
\hline & & Graduado Social & 1 & Bioprocesos & \\
\hline & & Psicología & 1 & & \\
\hline & & Turismo & 5 & & \\
\hline & & Derecho & 1 & & \\
\hline & & Relaciones Laborales & 1 & & \\
\hline & & Relaciones Internacionales & 2 & & \\
\hline
\end{tabular}

Fuente: Elaboración propia. 
Para matizar esta cuestión es preciso tener en cuenta que las preguntas de la encuesta se refieren únicamente a la formación reglada, cuando, como se detecta en otros estudios, uno de los rasgos de quienes ejercen profesionalmente en la EA es la inversión intensiva y permanente en formación no reglada (cursos, seminarios, congresos, etc.), constituyendo un pilar de su cultura corporativa (LOIS, 2007; MEIRA; PARDELLAS, 2010).

En cuanto a los perfiles formativos concretos, los datos disponibles muestran la enorme heterogeneidad del campo, dando cabida a personas de veintitrés titulaciones distintas, $\mathrm{y}$ su doble identidad. Entre las personas que poseen estudios universitarios, son mayoría quien cursaron titulaciones de la familia de las ciencias naturales, el 45,1\%, frente a quienes cursaron titulaciones ligadas a las ciencias sociales y jurídicas, el 38,5\%. A continuación aparecen quienes cursaron estudios técnicos o ingenierías, el 14,3\%, y un grupo minoritario con estudios de humanidades, el 2,2\% de la muestra.

$\mathrm{Al}$ analizar con detalle las titulaciones (tabla 1), destaca el predominio de quienes han cursado la Licenciatura en Biología o equivalente: el 35,6\%. Un segundo grupo está integrado por personas que poseen titulaciones de la familia de las ciencias de la educación, que suman el 22,2\% de quienes cursaron estudios superiores. Resulta curioso el estereotipo social que aún identifica la EA con la biología, cuando son muchas y muchos los profesionales cuya formación se enraíza en las ciencias de la educación.

Dentro del colectivo de profesionales cuya formación inicial remite a las ciencias de la educación, el 35,0\% cursó estudios de Magisterio, el 35,0\% la Licenciatura en Pedagogía y el 30,0\% la Diplomatura en Educación Social, dato relevante dado que esta titulación se incorporó en tiempos relativamente recientes a la oferta de las universidades gallegas (1996-1997 en la Universidad de Santiago de Compostela y Universidad de Vigo y 1998-1999 en la Universidade da Coruña). Esta distribución contrasta con el retrato que ofrece el Informe empleo verde en una economía sostenible (JIMÉNEZ HERRERO; LEIVA, 2010), en el que se citan los estudios de Magisterio como la única formación superior vinculada a la educación con presencia en el sector ocupacional de la EA. Esta discrepancia es otra llamada de atención sobre la carencia de estudios de calidad sobre la profesionalización de la EA en España, siendo necesario avanzar en la definición de "la figura y perfil de este tipo de profesionales, tanto a nivel formativo como profesional" (BAUTISTACERR0, 2010, p. 101).

El elevado grado de apertura del campo lleva consigo problemas de indefinición y dificultades para trazar los límites en relación a otros perfiles formativos $y$ profesiones colindantes $\mathrm{y}$, tal y como evidencian diversos estudios, condiciona un déficit de identidad interno que lleva a que las y los profesionales no se identifiquen cómo educadoras y educadores ambientales (GUTIÉRREZ ROGER, 2007), a la exhibición de una imagen pública confusa (SOTO; PARDELLAS, 2010), a la falta de visibilidad social y profesional y a lagunas importantes en la formación de las educadoras y educadores ambientales (BAUTISTA-CERRO, 2009). Esto dificulta su consolidación como campo autónomo, incorporando prácticas, enfoques y profesionales provenientes de otros espacios sociales que, según García (2004), se introducen en la EA sin aceptar las reglas del juego y sin considerar el bagaje previo del campo.

En este sentido, indagó Arias Ortega (2013) alrededor del significado de la expresión educación ambiental en construcción, interrogando a académicas y académicos del propio campo (Benayas, Caride, De Alba, Gaudiano, Gutiérrez, Leff, Meira, Morelos, Nuevo, Reyes, Sauvé y Tonatiuh). En sus respuestas aparece el disentimiento entre quien acepta tal estado en construcción y quien afirma que ya se encuentra en una etapa de consolidación; entre quien lo considera como una limitación y quien lo entiende como una cualidad o una virtud del propio campo. Argumenta González Gaudiano (apud 
ARIAS ORTEGA, 2013) que la valoración de este aspecto no se sitúa tanto en los años de trayectoria como en su posicionamiento respeto a la corriente principal de actividad, proponiendo una lectura atenta a la estabilidad profesional de la EA como sector profesional en el seno de las políticas públicas educativas y ambientales. La comparativa entre la situación profesional del campo entre 2007 y 2013 en Galicia pretende contribuir a esta línea de análisis.

\section{La evolución de la dimensión profesional de la EA en Galicia entre 2007 y 2013}

El objetivo principal de este apartado es valorar la evolución experimentada por el campo de la EA en Galicia desde el inicio de la crisis, en 2007, hasta el momento en que fue aplicado el cuestionario, comienzos de 2013. En la topología del campo atendiendo a los aspectos laborales, el estudio distingue cinco grandes sectores: el sector privado, que engloba también a las empresas cooperativas; el tercer sector, que agrupa a organizaciones no gubernamentales; el sector de las administraciones (central, autonómica y local); otros ámbitos subsidiarios de la EA, como pueden ser institutos de investigación o universidades; y una última categoría que agrupar a personas desempleadas y a quienes en 2007 o 2013 ejercían o ejercen como profesionales en un campo diferente a la EA.

Se aprecian alteraciones sustanciales en la estructura ocupacional del campo al comparar la situación en 2007 con la de 2013 (figura 3). Lo primero que destaca es la pérdida de activos en todos los sectores contemplados. El tercer sector es el que experimenta mayor erosión, perdiendo más de la mitad de quienes tenían en él su nicho ocupacional: si absorbía en 2007 al 19,8\% de los profesionales del campo, en 2013 solo al 7,9\%.

Figura 3- Distribución por frecuencias entre ámbitos laborales.

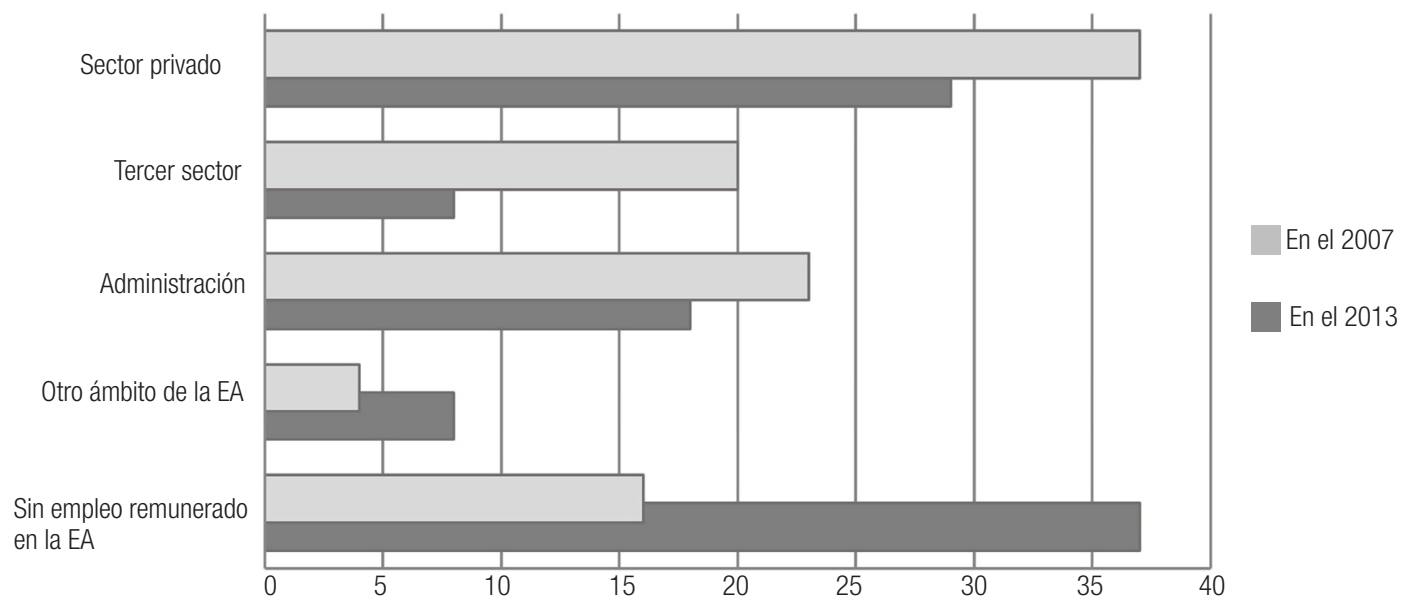

Fuente: Elaboración propia.

El análisis cruzado de los datos (figura 4) visualiza los tránsitos producidos entre los distintos sectores laborales en el intervalo considerado. Esta lectura aporta perspectivas muy negativas sobre la situación actual y un pronóstico preocupante sobre la evolución del campo a medio plazo.
Con respecto al período considerado, el sector más estable, con un menor trasvase de activos, es el de las administraciones públicas: siete de cada diez profesionales ocupados en él en 2007 continúan en 2013. Este mejor comportamiento puede atribuirse a que los recortes en los presupuestos 
públicos impactaron más tarde en el personal ligado a las administraciones que en otros colectivos, afectando primero y con más intensidad a los profesionales contratados en empresas privadas o en el tercer sector cuya financiación dependía en gran medida de fuentes públicas.

Por el contrario, el sector privado es el que más trasvases registra y el que sufre una retracción más aguda: el 43,2\% de quienes en 2007 estaban ocupados en él, en 2013 están en el paro o trabajan en ámbitos ajenos a la EA. Si este trasvase no se traduce en una pérdida de peso proporcional de este sector en relación al conjunto del campo (del 36,6\% en 2007 al $28,7 \%$ en 2013) se debe a que el $35 \%$ de los ocupados en el tercer sector en 2007 se pasaron en 2013 al ámbito de la empresa privada.

Figura 4- Trasvases entre campos laborales de 2007 a 2013.

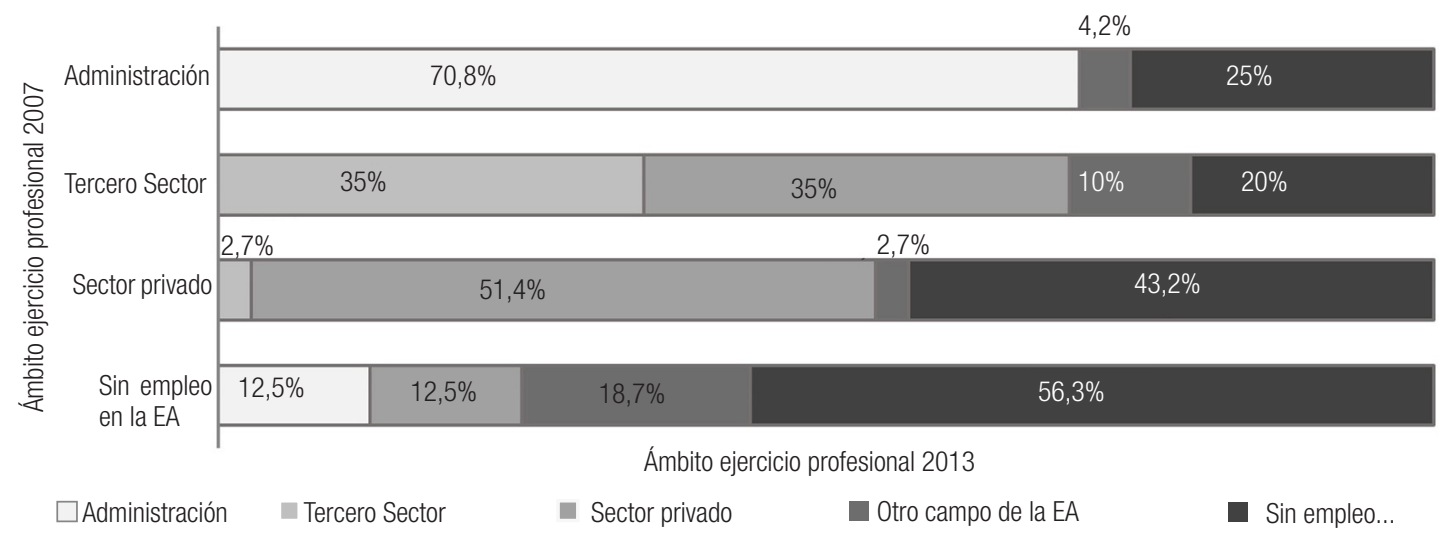

Nota: El eje vertical representa el sector en el que las personas estaban ocupadas en 2007 y las barras horizontales registran los sectores en los que se ubicaban profesionalmente a principios de 2013, visualizando los trasvases producidos.

Fuente: Elaboración propia.

Atendiendo a la evolución de la tipología de acciones de EA que desarrollan los y las profesionales de la muestra, la lectura comparada entre 2007 y 2013 ofrece un panorama desolador. Como se contempla en la figura 5, lo primero destacable es la disminución apreciable en todas las actividades contempladas. Las mayores caídas se registran en la gestión de equipamientos $(-41,5 \%)$ y en actuaciones ligadas a espacios naturales $(-35,4 \%)$; las menores caídas se registran en las actividades de promoción de la participación $(-5,5 \%)$ y la realización de itinerarios $(-9,5 \%)$. En todo caso, las actividades menos castigadas son las que menor peso tenían en el conjunto de tareas realizadas por los profesionales de la muestra. Del resto cabe destacar que son las actividades relacionadas con el turismo $(-17,9 \%)$ y el ocio $(-20,8 \%)$ las que mejor resisten el embate de la crisis. Este mejor comportamiento se puede atribuir a que son actividades ligadas a campos fronterizos a la EA, convirtiéndose en refugios ante la dificultad para mantener ocupaciones con un perfil educador más definido. La migración profesional hacia sectores de ocupación menos refractarios a la lógica de mercado, como los ligados al turismo o al ocio, es una alternativa de supervivencia que puede trivializar las prácticas de la EA, convirtiéndola en una "estampa comercial al estilo Port Aventura y Warner Bros" (CALVO; GUTIÉRREZ, 2007, p. 80) y desvirtuando su dimensión pedagógica y crítica. 
Figura 5- Comparativa entre 2007 y 2013 en relación al tipo de actividades que se realizan.

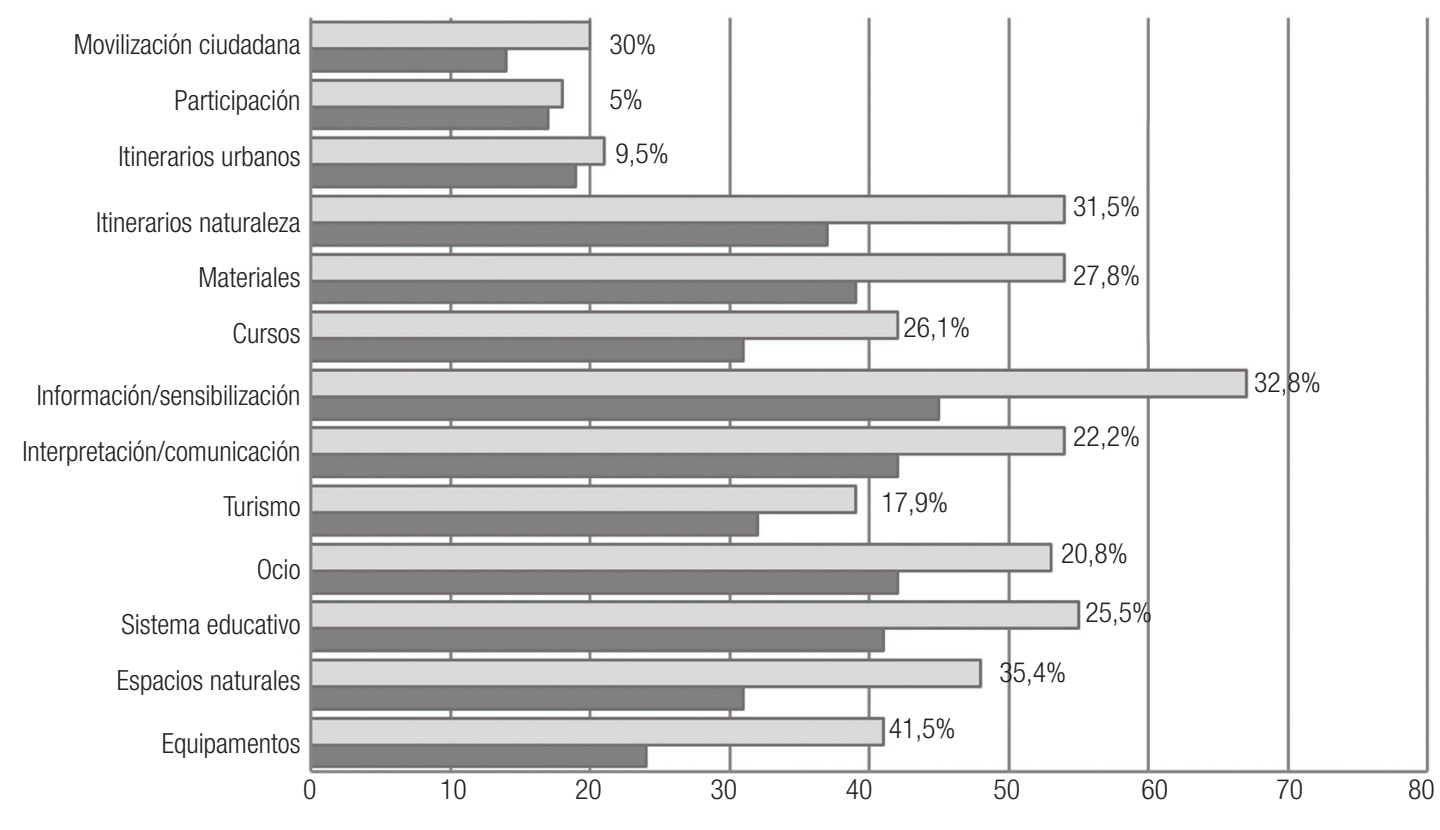

En el 2007 En el 2013

Nota: Distribución por frecuencias. Los porcentajes reflejan el índice de pérdida de actividad entre ambas anualidades. Fuente: Elaboración propia.

Como ya se destacó, las actividades profesionales en equipamientos de EA son las que sufren mayor desgaste $(-41,5 \%)$. Es el resultado del cierre de la mayor parte de los equipamientos de EA de titularidad pública, sumado a los drásticos recortes aplicados en los pocos que mantienen algún tipo de actividad, y a la difícil supervivencia de los equipamientos de titularidad privada, afectados por la disminución de los presupuestos públicos y la retracción de una demanda que nunca fue especialmente intensa.

La crisis desvela que la apertura de equipamientos de EA tiene que ir precedida por un proyecto educativo, social y presupuestario bien fundamentado, coherente con las necesidades del entorno y explícito. Un proyecto con un horizonte a medio y largo plazo que parta de una premisa elemental: que son los recursos humanos y el programa pedagógico, más que la existencia de una infraestructura, los pilares para concretar sus funciones sociales, ambientales y educativas. La situación actual también evidencia que el impulso de los equipamientos de EA, en Galicia y en España, ha sido demasiadas veces una coartada para legitimar operaciones que tenían más que ver con intereses de empresas dedicadas a la construcción que con las necesidades socio-educativas derivadas de la crisis ambiental. Serantes califica la situación de los equipamientos de EA en Galicia como desalentadora y contradictoria,

[...] desalentadora porque la mayor parte de los centros de carácter público están cerrados, y contradictoria porque las Administraciones siguen invirtiendo cantidades millonarias en la creación de nuevos centros que, con total certeza, acabarán cerrados como los que ya existían. (2013, p. 226).

La dependencia del sector de las iniciativas de las diferentes administraciones, 
por una parte; y las condiciones de precariedad en las que los profesionales ligados a la EA ya venían desarrollando su actividad, por otra (MEIRA; PARDELLAS, 2010), son propiedades estructurantes del campo que la crisis agudiza y amplifica. En esta situación de debilidad es comprensible que la praxis educativo-ambiental se aleje cada vez más de los fundamentos $\mathrm{y}$ objetivos de cambio socio-ambiental que justifican su existencia.

El análisis de la situación contractual de los y de las profesionales de la EA entre 2007 y 2013 desvela la tradicional precariedad del campo y los daños que está produciendo la crisis en Galicia. Las tipologías contractuales asociadas con condiciones laborales de mayor calidad y estabilidad (laboral indefinido, a tiempo completo, a tiempo parcial, de duración indeterminada) sólo suman el 51\% de la muestra en 2007, menguando al 38\% en 2013. Las personas que se declaran trabajadoras autónomas duplican su presencia en el conjunto de la muestra: del 9\% en 2007 al 17\% en 2013. Este dato trasluce los cambios que la crisis impone en la estructura del mercado laboral, en general, $\mathrm{y}$ en el de la EA, en particular. El incremento de profesionales que se declaran autónomos se hace en detrimento de figuras contractuales más estables, indicio de una mayor precarización que agrava un déficit del sector previo a la crisis (SOTO; PARDELLAS, 2010).

El dato más preocupante es la evolución del desempleo. En términos porcentuales supone hablar de una tasa de paro en el campo de la EA que alcanza en 2013 al 30\% del colectivo, mientras que en 2007 era del 5,7\% $0^{5}$. Esta cifra es superior a la tasa de paro española en el primer trimestre de 2013, el 27,16\%, y muy superior a la gallega, el 22,35\% en el mismo trimestre (INSTITUTO NACIONAL DE ESTADÍSTICA, 2013). Es decir, no solo se multiplicó por seis la tasa de paro entre los trabajadores de la EA,

5 - Para calcular la tasa de paro en 2007 es preciso descontar a las personas inactivas (becarios, estudiantes y voluntarios). La de 2013 puede calcularse sobre el $100 \%$ de la muestra dado que únicamente aparecen dos personas como voluntario/a con remuneración informal. sino que también pasó de estar por debajo de las tasas de paro gallega y española $(8,6 \%$ y $7,6 \%$, respectivamente, en 2007), a superarlas claramente. Este dato es un poderoso indicador de que la crisis ha afectado de manera más aguda a este campo profesional que a otros.

También resulta preocupante la lectura en clave de género, apreciándose diferencias significativas entre la tasa de desempleo femenina y la masculina: en 2013 la tasa de desempleo femenina en el sector alcanzó el 37,7\%, triplicando la masculina (12,5\%), mientras en 2007 la diferencia era menor: el $5,8 \%$ en mujeres y el 3,1\% en hombres.

Tabla 2- Distribución por frecuencias según puesto de trabajo

\begin{tabular}{c:c:c}
\hline & 2007 & 2013 \\
\hline Educador/a ambiental & 20 & 9 \\
Coordinador/a de programas, proyectos y & 7 & 7 \\
Monitor/a de educación ambiental & 12 & 5 \\
Guía intérprete medioambiental & 6 & 1 \\
Comunicador/a ambiental & - & 1 \\
\hline Técnico/a de medio ambiente & 5 & 6 \\
Técnico/a en gestión forestal y conservación de & 1 & 1 \\
Brigadista forestal & - & 1 \\
Topógrafa de campo & 1 & - \\
Técnico/a xuventude & 2 & 1 \\
Animador/a sociocultural & 1 & 1 \\
Técnico/a en desenvolvemento territorial & - & 1 \\
Técnico/a en comunicación y participación & 1 & - \\
pública & 1 & - \\
Técnico/a en Cooperación al Desarrollo & 17 & 43 \\
Guía turístico & - & 1 \\
Consultor/a & 2 & 4 \\
Investigador/a & 1 & 2 \\
\hline No trabaja o lo hace en otro sector & 17 &
\end{tabular}

Fuente: Elaboración propia.

La lectura del impacto de la crisis sobre la EA se agudiza por el hecho de que, como ya se destacó, el 88,1\% de los y las profesionales del campo poseen estudios superiores. La tasa de paro entre la población activa española con estudios superiores era, en 2012, del 15,2\% (INSTITUTO Nacional de Estadística, 2012), porcentaje que se duplica en este estudio, alcanzando el 30,0\%. 
Significativamente, la tasa de paro registrada en 2007 entre los trabajadores y trabajadoras con estudios superiores en el conjunto de la población española fue del 5,3\% (INSTITUTO NACIONAL DE ESTATÍSTICA, 2007), cifra equiparable a la registrada por la muestra en el mismo año, el 5,7\%.

Otra forma de valorar la evolución del campo de la EA en el período considerado atiende al perfil ocupacional de sus profesionales. En la encuesta se preguntaba el puesto de trabajo a través de una pregunta abierta. La información obtenida (tabla 2) refleja la diversidad de un campo que acoge a personas de diecisiete perfiles diferenciados, algunos de ellos directamente vinculados a la EA (primer cuadrante) y otros campos profesionales, como las profesiones ambientales o del ámbito sociocultural (segundo y tercer cuadrante). Esta diferenciación, permite apreciar el mayor impacto de la crisis en el campo da la EA en comparación con eses sectores afines (figura 6), ya que mientras los puestos asociados a otros campos se mantienen más o menos estables, aquellos vinculados directamente a la EA experimentan una caída del 50\%, agravando la lectura sobre la pérdida de empleo en el sector.

Figura 6- Comparativa entre 2007 y 2013 en función del campo profesional.

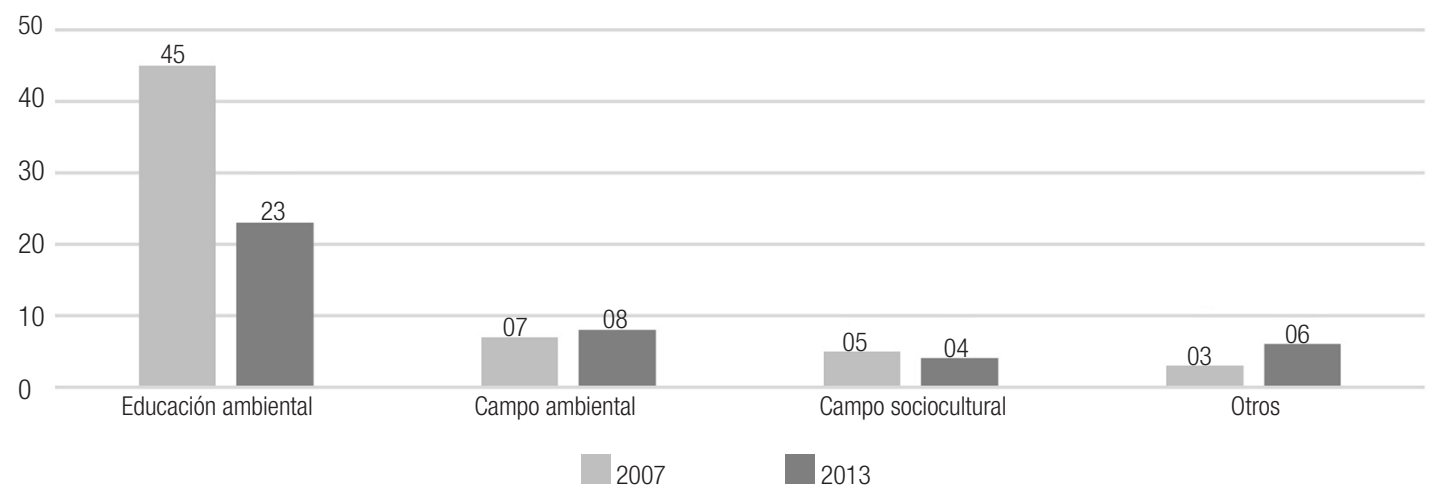

Educación ambiental: educador/a ambiental; monitor/a ambiental; coordinador/a de programas, proyectos y centros de educación ambiental; guía intérprete medioambiental; comunicador/a ambiental.

Campo ambiental: técnico/a de medio ambiente; en gestión forestal y conservación de la naturaleza; brigadista forestal; topógrafo/a de campo

Campo sociocultural: animador/a sociocultural; técnico/a en juventud; en desarrollo territorial; en comunicación y participación pública; en cooperación al desarrollo; guía turístico/a

Otros: consultor/a; investigador/a

Fuente: Elaboración propia.

La evolución salarial amplia la visión de la situación socio-profesional en el marco de la crisis. Si la moda de ingresos se situaba en 2007 en las franjas de 901 a $1.200 €$ y de 1.501 a $1.800 €$, en 2013 se rebaja para situarse entre los $301 \mathrm{y}$ los $600 €$ mensuales. Atendiendo a la variable de género, mientras la mitad de los hombres (48,8\% en 2007 y 44,7\% en 2013) cobran más de $1.500 €$ mensuales, prácticamente la mitad de las mujeres (48,4\% en 2007 y 44,9\% en 2013) perciben menos de $1.000 €$. Esta asimetría contrasta con el hecho de que no se detectan diferencias significativas en el nivel de cualificación en relación al género.
La lectura de estos datos permite extraer tres conclusiones importantes en relación al salario. 1) Resulta evidente que las condiciones salariales de los profesionales de la EA en Galicia empeoraron en el período considerado. 2) Tanto en 2007 como en 2013, pero de manera más acusada en 2013, los niveles salariales no se corresponden ni con el nivel formativo ni con las responsabilidades que se asumen. 3) Se aprecia una creciente polarización en las franjas salariales, con una mayoría que percibe salarios incluso por debajo del mínimo interprofesional ${ }^{6}$

6 - En España, el salario mínimo interprofesional era de 570,60 € en 2007 y de $645,30 €$ en 2013. 
(en 2013, el 35\% afirma cobrar menos de 900 $€$ mensuales y el $25 \%$ menos de $600 €$ ) y una minoría que disfruta salarios relativamente altos para el bajo promedio del sector: solo el $12 \%$ de la muestra percibe más de $1.500 €$ mensuales en 2013, igual que en 2007.

Analizando el número de días trabajados en el año precedente (2012), únicamente el 30\%, superó los 201 días (año laboral completo); el resto está por debajo de esta cifra. Casi el mismo porcentaje, el 29\%, trabajó 100 días o menos, es decir, estuvieron en paro durante medio año o más. De este porcentaje, dos tercios -el 18\%- trabajaron el equivalente a tres meses o menos. Atendiendo a este indicador, se constata de nuevo el mayor impacto diferencial de la crisis sobre el campo de la EA respecto al panorama laboral en su conjunto o a sectores afines. El porcentaje de temporalidad se sitúa en Galicia en un 25,7\% y en España en un 25\%. Atendiendo al sector de actividad económica en el que se ubica, actividades profesionales, cientificas y técnicas, la diferencia aún es más acentuada, ya que la temporalidad en este sector es del 23,1\% (INSTITUTO NACIONAL DE ESTADÍSTICA, 2013). La comparación con 2007 es imposible, pero el dato es revelador: menos de uno de cada cuatro profesionales estuvo ocupado durante todo el año 2012, evidencia contundente de la depresión que afecta al campo de la EA. La crisis ha acentuado las situaciones de estacionalidad y discontinuidad laboral ya endémicas en el campo antes de su advenimiento (SOT0; PARDELLAS, 2010).

\section{La proletarización del campo de la educación ambiental}

La imposición del discurso neoliberal ha dejado en el olvido conceptos de gran utilidad para entender la evolución de algunas profesionales socio-educativas en un contexto de crisis socio-económica como el actual. El concepto de proletarización es uno de esos recursos analíticos interesadamente olvidados. El examen retrospectivo de la evolución de la profesionalización de la EA en Galicia permite observar cómo se han seguido las fases del proceso de proletarización señaladas por Wilensky (1964) más de medio siglo atrás. La EA comenzó en los años 80 como una actividad ejercida por personas sin formación específica, inscritas en colectivos ecologistas o de renovación pedagógica en los que el propio campo va construyendo su identidad. A finales de los años 80 y en la década de los 90 se crearon programas formativos que favorecieron la constitución y el acceso a un corpus de conocimientos propio: cursos, jornadas, especializaciones, estudios de posgrado y doctoramiento, formación profesional. A partir de ese momento se comenzaron a definir perfiles profesionales específicos, creándose asociaciones y agrupaciones dirigidas a defender los intereses corporativos del campo: la Sociedade Galega de Educación Ambiental (SGEA) en el año 2004, en Galicia, y la Federación de Entidades de Educación Ambiental (FEEA), a nivel del Estado español, en 2008, entre otras. Este proceso no fue tampoco rápido ni fácil, implicó el esfuerzo y la dedicación de personas que se identificaban como educadoras y educadores ambientales y apostaron decididamente por consolidar su perfil profesional y una esfera laboral asociada al mismo. Cuando aún se estaban dando los primeros pasos para consolidar profesionalmente el campo de la EA, la irrupción de la crisis ha supuesto un claro retroceso respecto a los logros alcanzados.

La lectura de la situación presente de la EA en Galicia revela claramente la pérdida de autonomía que sufren las y los profesionales del campo sobre el ejercicio de su trabajo, en un proceso de proletarización en el que "tras las pérdida de control sobre los términos económicos del trabajo está la pérdida del control sobre qué trabajo debe ser realizado y sobre cuál debe ser el objetivo del trabajo" (RODRÍGUEZ ÁVILA, 2008, P. 55).

Derber (1983) propuso una serie de indicadores para ponderar el grado de profesionalización o proletarización de un campo: la autonomía, la cualificación, la 
satisfacción con el trabajo y la identificación con los objetivos de la organización. Los datos de la encuesta permiten un análisis aplicado de estas categorías a la situación actual de la EA en Galicia (tabla 3).

Tabla 3- Indicadores de proletarización del campo.

\begin{tabular}{cc:c:c:c}
\hline & & $\bar{X}$ & $\sigma$ & $n$ \\
\hline \multirow{2}{*}{ Nivel de } & 2007 & 2,76 & 1,512 & 100 \\
cualificación & 2013 & 1,98 & 1,848 & 100 \\
& 2007 & 3,85 & 1,012 & 84 \\
\multirow{3}{*}{ Satisfacción } & 2013 & 3,12 & 1,414 & 73 \\
& 2007 & 3,49 & 1,097 & 81 \\
\multirow{3}{*}{ Coherencia } & 2013 & 3,19 & 1,386 & 69 \\
& 2013 &
\end{tabular}

Fuente: Elaboración propia.
En lo que se refiere al nivel de cualificación, valorándose en una escala de uno a cinco $^{7}$, la media se situaba en 2,76 puntos en el año 2007, sufriendo un acusado descenso hasta el 1,98 a comienzos de 2013. Los puestos que resisten en mejores condiciones el embate de la crisis son aquellos asociados a un nivel de cualificación más elevado. Esto se traduce también en una mayor polarización del campo, siendo que la desviación típica pasa de 1,51 a 1,85 puntos.

También descienden los niveles de satisfacción (figura 7). La media en el nivel de satisfacción se sitúa en 3,85 puntos sobre cinco en 2007, descendiendo a 3,12 puntos

Figura 7- Nivel de satisfacción respecto al ejercicio de su trabajo.

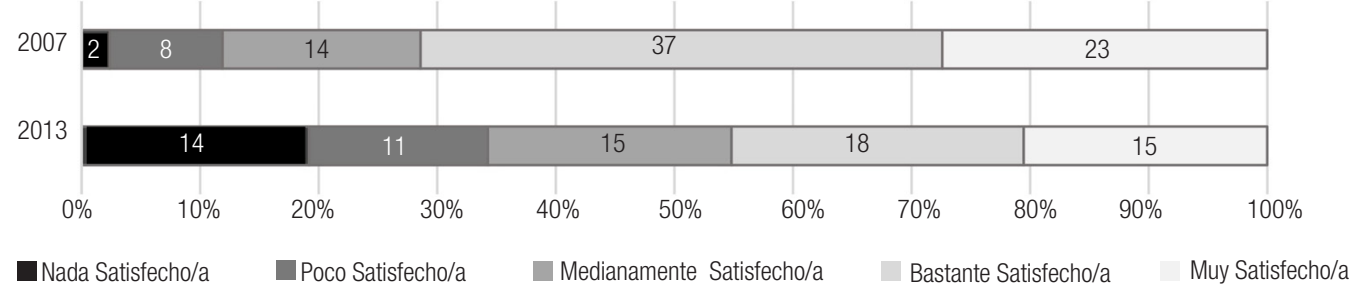

Fuente: Elaboración propia.

en 2013. La lectura más preocupante de este indicador se obtiene al atender a aquellas personas que se sitúan en los niveles más bajos. En 2007, el 11,9\% de las educadoras y educadores ambientales indicaba estar nada o muy poco satisfecho respecto al ejercicio de su trabajo, categorías que suman al 34,25\% de la muestra en 2013. Esta es una cifra alarmante que da cuenta del elevado grado de descontento de las y los profesionales del campo en su desempeño laboral. También aumenta, en este caso, la polarización del campo, pasando de una desviación típica de 1,01 puntos en 2007 a 1,41 en 2013.

En lo que se refiere a su autonomía o nivel de identificación con los objetivos de la EA, existe entre las educadoras y educadores ambientales la consciencia de que su práctica profesional no es totalmente coherente con los presupuestos de la EA. Así lo refleja la encuesta (figura 8), que sitúa la media de la valoración de la correspondencia entre lo que consideran que es la EA y el ejercicio real de su trabajo en 3,49 puntos sobre cinco en 2007 y en 3,19 en 2013. Si bien la incidencia de la crisis parece limitada atendiendo a estas puntuaciones, el aumento de la varianza, pasando del 1,09 en 2007 a 1,38 en 2013, refleja la polarización del campo. El aspecto más crítico se aprecia al ponderar el porcentaje de personas que se sitúan en la valoración "1", referida a una escasa o nula identificación de su trabajo con la EA. Si el $3,9 \%$ se identificaba con esta situación en 2007 , cinco años más tarde refleja la realidad de un $16,05 \%$ de la muestra.

7- Según los niveles de cualificación profesional establecidos por el INCUAL - Instituto Nacional de Cualificaciones (2008). 
Figura 8- Escala de valoración del grado de coherencia de sus prácticas profesionales.

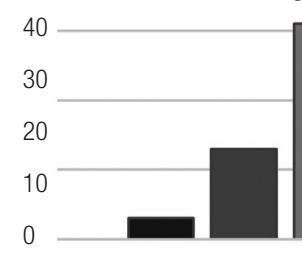

0

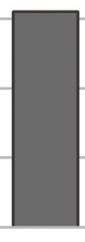

2007

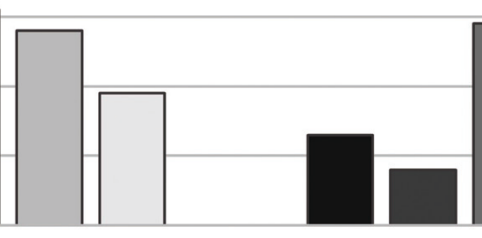

2013

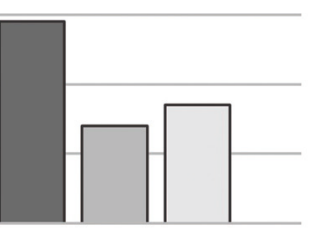

Fuente: Elaboracion propia.

La incidencia de lógicas e intereses ajenos al desarrollo de la EA produce inquietud entre las y los profesionales del campo, conscientes de esta situación pero obligadas a aceptar estas dinámicas para poder subsistir laboralmente. Esta situación coloca a los y las integrantes del campo en la disyuntiva entre mantener una coherencia en el ejercicio profesional o intentar asegurar la permanencia del campo y los puestos de trabajo a él asociados, limitando su dimensión transformadora y truncando los avances en el proceso de profesionalización realizados en las últimas décadas.

\section{Conclusión: del decenio de oro a la} depresión

El análisis de la situación socioprofesional de una centena de educadores y educadoras ambientales en Galicia evidencia el profundo impacto de la crisis. El último lustro del siglo pasado y el primero del siglo XXI conformaron, vistos desde el presente, el decenio de oro de la EA en Galicia y, posiblemente, en España. Calificar así dicho período no implica considerar que la situación profesional y laboral del colectivo fuera óptima, dada la precariedad endémica que reflejan indicadores como la tipología de contrato o el nivel salarial; pero sí que ese decenio se caracterizó por la creación de empleo en el sector, situando la tasa de paro por debajo de la media gallega y española. Los datos sobre incorporación profesional al campo permiten vincular este apogeo a la articulación de políticas públicas que proyectaron al sector hacia el futuro, visualizando la importancia de las mismas en su proceso de institucionalización y consolidación. En Galicia, la elaboración de la Estratexia Galega de Educación Ambiental (EGEA en el año2000), a nivel institucional, o la constitución de la Sociedade Galega de Educación Ambiental (SGEA en el año 2001), a nivel social, fueron hitos relevantes de ese impulso.

La crisis truncó lo poco avanzado en esta línea. Como evidencia este estudio, la crisis está actuando como el caballo de Atila. La tasa de paro en 2013, momento en el que se hace la encuesta, multiplica por cuatro la registrada en 2007. Las situaciones contractuales han empeorado, agudizándose las condiciones de precariedad pre-existentes. Así, por ejemplo, el salario medio se ha reducido significativamente. Los y las profesionales valoran como peor su situación y aprecian que su trabajo tiene cada vez menos que ver con los principios y las finalidades de la EA. Es un retrato nada benevolente de la EA que entra en contradicción con la supuesta importancia que la labor educativo-ambiental tiene para avanzar hacia una sociedad sostenible en lo ambiental y en lo social.

Este panorama de ultra-precarización refleja que la atención educativa a la problemática ambiental no es prioritaria. La EA es tratada como un campo social prescindible. Así lo indica, por ejemplo, el mayor impacto de la crisis en la situación de sus profesionales que en otros sectores. En esta coyuntura, la EA aparece como una práctica incómoda de la que, con la coartada de la crisis, se 
puede prescindir sin asumir costes sociales o políticos. Si en las últimas décadas se había avanzado en la construcción de un Estado de Bienestar, la cuestión ambiental no ha llegado a consolidarse socialmente como un pilar básico del mismo. Este déficit se incrementa en el caso de la EA por el hecho de que sus presupuestos éticos e ideológicos entran en colisión con las lógicas que vertebran el mercado y los intereses hegemónicos en él (CARIDE; MEIRA, 2001; MEIRA, 2006).

Las debilidades internas del campo facilitan esta tarea de desmantelamiento. Estas debilidades están relacionadas con una identidad corporativa poco definida, reflejada tanto en la diversidad de perfiles profesionales como formativos. Entre las personas que participaron en este estudio se identifican veintitrés titulaciones, vinculadas a cuatro ramas de conocimiento distintas. La multidisciplinariedad es una característica propia de la EA que aporta una lectura compleja de la problemática ambiental, pero también actúa como lastre en su consolidación profesional. Se hace necesario avanzar en la configuración de una formación específica, más allá de la voluntariedad de ser abordada dentro de otras titulaciones (magisterio, educación social, biología, ciencias ambientales, etc.) en las que se enmarca y de las que adquiere sus lógicas disciplinares, no siempre acordes a las necesidades del campo.

Los resultados demandan dos tipos de acciones complementarias. Institucionalmente, es preciso recuperar la construcción de una política pública de EA que debe tener en la Administración Autonómica su principal actor responsable, restableciendo la inversión pública y las acciones estratégicas para salir de la situación de atonía y depresión actual (MEIRA, 2014). Desde la óptica corporativa, debe ser el propio sector, apoyado en aquellos colectivos de la sociedad civil más concienciados sobre la naturaleza estructural de la crisis socioambiental, el que demande su protagonismo en la construcción participada de dichas políticas, a partir de una transformación de la gestión pública que otorgue poder a las personas y comunidades fortaleciendo "su capacidad de resistencia a la dominación capitalista de sus vidas (trabajo) y de sus espacios (ambiente)" (SORRENTINO et al., 2005, p. 287). En todo caso, la EA debe aspirar a situar la cuestión ambiental no sólo como parte de la crisis, sino como parte de las soluciones ineludibles a la misma, transcendiendo los factores coyunturales y apuntando a sus causas últimas: un modelo de desarrollo que ignora los límites biofísicos del planeta y que no redistribuye equitativamente los recursos y los servicios que la biosfera nos presta.

\section{Referencias}

ARIAS ORTEGA, Miguel Ángel. La construcción del campo de la educación ambiental: análisis, biografías y futuros posibles. Guadalajara-Jalisco: Universitaria, 2013.

BAUTISTA-CERRO, María José. Perfil profesional y formativo de los educadores ambientales en el marco del Espacio Europeo de Educación Superior. 2009. 221 p. Tesis (Doctorado) - Facultad de Educación, Universidad Nacional de Educación a Distancia, Madrid, 2009.

BAUTISTA-CERRO, María José. Autoimagen profesional de los educadores ambientales: una contribución al estudio de las profesiones educativas. Pedagogía Social, Sevilla, n. 17, p. 97-106, 2010.

BOURDIEU, Pierre. Razones prácticas: sobre la teoría de la acción. Barcelona: Anagrama, 1997.

BRANDÃO, Zaia. Operando com conceitos: com e para além de Bourdieu. Educação e Pesquisa, São Paulo, v. 36, n. 1, p. 227-241, 2010.

CALVO, Susana; GUTIÉRREZ, José. El espejismo de la educación ambiental. Madrid: Morata, 2007. 
CARIDE, José Antonio. La pedagogía social como soporte para una intervención educativa en la vejez. In: BONHO, Miriam (COORD.); ENCONTRO IBERO-AMERICANO, 1., 2002, Caxias do Sul. Anais do... Caxias do Sul: Universidade de Caxias do Sul, 2002. p. 31-37.

CARIDE, José Antonio; MEIRA, Pablo Ángel. Educación ambiental y desarrollo humano. Barcelona: Ariel, 2001.

DERBER, Charles. Managing Professionals: ideological proletarization and post-industrial labor. Theory and Society, Davis, v. 12, n. 3, p. 309-341, 1983.

GARCÍA, José Eduardo. Educación ambiental, constructivismo y complejidad. Sevilla: Díada, 2004.

GONZÁLEZ GAUDINIANO, Edgar. La profesionalización de los educadores ambientales: puntos críticos para una propuesta curricular. In: GONZÁLEZ, Edgar; GUILLÉN, Fedro Carlos (Ed.). ¿Profesionalizar la educación ambiental? Ciudad de México: Universidad de Guadalajara; Semarnap, 1998. p. 17- 36.

GUTIÉRREZ ROGER, Xulio. Aproximación al perfil socioprofesional de los educadores y educadoras ambientales en Galicia. In: PUJOL, Rosa María; CANO, Luis (Ed.). Nuevas tendencias en investigaciones en educación ambiental. Madrid: Organismo Autónomo Parques Nacionales del Ministerio de Medio Ambiente, 2007. p. 463-482.

IMEDES - Instituto Mediterráneo para el Desarrollo Sostenible. Perfiles de las ocupaciones medioambientales y su impacto sobre el empleo. Madrid: INEM-Ministerio de Empleo y Asuntos Sociales, 2008.

INEM - Instituto Nacional de Empleo. Estudio marco sobre sectores y ocupaciones medioambientales. Madrid: Servicio Público de Empleo Estatal, 2006.

INSTITUTO Nacional de Estadística. In: ENCUESTA ANUAL DE COSTE LABORAL, 2013. Coste laboral 2013. Madrid: INE, 2014. Disponible en: <http://www.empleo.gob.es/es/estadisticas/mercado_trabajo/index.htm>. Acceso en: 23 jul. 2015.

Instituto Nacional de Estadística. In: ENCUESTA DE POBLACIÓN ACTIVA, 2012. Encuesta... Madrid: INE, 2013. Disponible en: $<$ http://www.ine.es/prensa/epa_tabla.htm>. Acceso en: set. 2015.

INSTITUTO Nacional de Estadística. ENCUESTA DE POBLACIÓN ACTIVA, 2007. Encuesta... Madrid: INE, 2008. Disponible en: $<$ http://www.ine.es/prensa/epa_tabla.htm>. Acceso en: set. 2015.

INSTITUTO Nacional de las Cualificaciones. Catálogo nacional de cualificaciones profesionales. Madrid: Ministerio de Educación y Ciencia, 2008.

INSTITUTO SUPERIOR DE MEDIO AMBIENTE. Guía infoempleo ISM de profesionales del medio ambiente. Madrid: ISMA, 2012. Disponible en: <ttp://blog.infoempleo.com/wp-content/uploads/2012/11/Guia-ISM-Digital.pdf>. Acceso en: 23 jul. 2015.

IRCUAL - Instituto Regional de las Cualificaciones. Estudio de los perfiles existentes y las necesidades formativas en el ámbito de las actividades ligadas al medioambiente. Madrid: Comunidad de Madrid, 2009.

JIMÉNEZ HERRERO, Luis Miguel; LEIVA, Ana (Dir.). Empleo verde en una economía sostenible. Madrid: Fundación BiodiversidadOSE, 2010.

LOIS, Antón. Ser educador ambiental en formación permanente. Educación Social, Barcelona, n. 37, p. 74-84, 2007.

MEIRA, Pablo Ángel. Crisis ambiental y globalización: una lectura para educadores ambientales en un mundo insostenible. Trayectorias, Nueva León, v. 8, n. 20-21, p. 110-123, 2006.

MEIRA, Pablo Ángel. Dez reflexións sobre a educación ambiental en Galicia: ollando máis alá da crise. In: Espazo Ecosocialista Galego (Ed.). Ecoloxía política. Olladas dende Galicia. Santiago de Compostela: Obencomun, 2014. p. 157-176.

MEIRA, Pablo Ángel. Outra lectura da historia da educación ambiental e algunha nota sobre a crise do presente. Ambientalmente Sustentable, A Coruña, v. 4, n. 8, p. 16-43, 2009.

MEIRA, Pablo Ángel; PARDELLAS, Miguel (Coord.). El Proyecto Fénix: proceso de diagnóstico y actualización de la estrategia gallega de educación ambiental. Santiago de Compostela: Xunta de Galicia-CEIDA, 2010. 
MUÑOZ-PEDREROS, Andrés. La educación ambiental en Chile, una tarea aún pendiente. Ambiente \& Sociedade, São Paulo, v. 17, n. 3, p. 177-195, 2014.

OLIVER, Miquel. Las profesiones en tiempos de crisis. In: ESCUDERO, Clotilde; OLIVER, Miquel; SERANTES, Araceli (Coord.). Los equipamientos de educación ambiental en España: calidad y profesionalización. Madrid: Organismo Autónomo Parques Nacionales-Ministerio de Agricultura, Alimentación y Medio Ambiente, 2013. p. 53-58.

RODRÍGUEZ ÁVILA, Nuria. Manual de sociología de las profesiones. Barcelona: Universitat de Barcelona, 2008.

SERANTES, Araceli. Equipamientos de educação ambiental en la Galicia; quenes são, de donde vêm, para donde vão. In: ALMEIDA, Fátima.; PINTO, Joaquim; SILVA, Joana (Coord.). Aprender fora de portas: redes, recursos e potencialidades. Leiría: Associação Portuguesa de Educação Ambiental, 2013. p. 221-227.

SORRENTINO, Marcos et al. Educação ambiental como política pública. Educação e Pesquisa, São Paulo, v. 31, n. 2, p. 285-299, 2005.

SOTO, Susana. El contexto socioprofesional de la educación ambiental y regulación del sector. Educación Social, Barcelona, n. 35, p. 56-73, 2007.

SOTO, Susana; Pardellas, Miguel. La profesionalización na educación ambiental en Galicia. Santiago de Compostela: Xunta de Galicia-CEIDA, 2010.

WILENSKY, Harold. The professionalization of everyone? American Journal of Sociology, Chicago, v. 70, n. 2, p. 137-158, 1964.

Recibido en: 02.10.2015

Aprobado en: 17.05.2016

Pablo Ángel Meira Cartea es profesor titular de Educación Ambiental en la Universidad de Santiago de Compostela. Miembro del Grupo de Investigación en Pedagogía Social y Educación Ambiental (SEPA). Premio María Barbeito de Investigación Pedagógica (2009). Director del Proyecto Resclima (www.resclima.info).

María Barba Núñez es doctora en Ciencias de la Educación por la Universidad de Santiago de Compostela, licenciada en Pedagogía y diplomada en Educación Social. Actualmente es presidenta de la Sociedad Galega de Educación Ambiental.

Juan José Lorenzo Castiñeiras es doctor en Ciencias de la Educación por la Universidad de Santiago de Compostela y licenciado en Sociología por la Universidad de A Coruña. Interés en los campos de la sociología rural, los tiempos sociales, los estudios de género y educación ambiental. 